\title{
The Fabrication and Properties Characterization of Wood-Based Flame Retardant Composites
}

\author{
Xia He, ${ }^{1}$ Xianjun Li, ${ }^{1}$ Zhu Zhong, ${ }^{1}$ Yongli Yan, ${ }^{1}$ Qunying Mou, ${ }^{2}$ \\ Chunhua Yao, ${ }^{1}$ and Chun Wang ${ }^{1}$ \\ ${ }^{1}$ Material Science and Engineering College, Central South University of Forestry and Technology, Changsha, Hunan 410004, China \\ ${ }^{2}$ College of Science, Central South University of Forestry and Technology, Changsha, Hunan 410004, China
}

Correspondence should be addressed to Xianjun Li; lxjmu@163.com

Received 31 March 2014; Accepted 9 May 2014; Published 26 May 2014

Academic Editor: Sanqing Huang

Copyright (C) 2014 Xia He et al. This is an open access article distributed under the Creative Commons Attribution License, which permits unrestricted use, distribution, and reproduction in any medium, provided the original work is properly cited.

\begin{abstract}
Wood-based flame retardant composites were fabricated based on vacuum-pressure impregnating method after high intensive microwave pretreatment. The effects of ammonium polyphosphate (APP) and modified nano-zinc borate (nZB) addition on flame-retardation and smoke-suppression properties of wood were investigated by cone calorimeter method (CONE) and thermogravimetric analysis (TGA). The results show that the heat release rate (HRR), peak heat release rate (pk-HRR), and total heat release (THR) of APP-treated woods decreased greatly with increasing concentration of APP. However, mean yield of CO (Mean COY) of APP-treated wood was much higher (3.5 times) than that of untreated wood. Compared with wood treated with APP at a concentration of $15 \%$, the total smoke product (TSP), Mean COY, and pk-HRR decreased by $78.4 \%, 71.43 \%$, and $31.23 \%$, when wood was treated with APP and nZB (both concentrations were at 15\%). APP and nZB have synergistic effects of flameretardation and smoke-suppression. Nano-zinc borate combined with APP would be used in wood-based composites to efficiently retard flame, reduce fire intensity, and decrease noxious $(\mathrm{CO}) /$ smoke release.
\end{abstract}

\section{Introduction}

With the increase in living conditions and growing concerns about environmental protection for people, wood is attracting gradually more attention for its particular characteristics and excellent environmentally friendly properties. However, its marked combustibility may cause unexpected potential fire hazards. Flame-retardant treatment of a wood is one of the most effective ways to protect it from fire. Upon growing awareness of environmental protection and consumer safety, requirement standards to flame retardants have been raised accordingly. In addition to flame-retard capability, properties, such as being harmless to human, animals, and plants and less release of smoke and toxic gases when combusted, are important indices for people to choose a flame retardant. Inorganic flame retardants which have good thermal stability, less releases of smoke, and corrosive toxic gases are in line with requirements of our society for environment protections and have been widely used in flame retardation treatments of plastic, wood, and other materials [1].
Ammonium polyphosphate (APP), an inorganic fireretardant, is a well-known phosphorus flame retardant due to its low cost and high flame-retard capacity, accounting for about $20 \%$ of flame retardants in the industry [2]. However, APP also catalytically generates a lot of smokes and poisonous gases during combustion [3]. Therefore, it is desirable to improve APP as a better flame retardant of wood which can reduce the smoke release from pyrolysis of wood, thus minimizing air pollution to the ecological environment. Adding some reagents into APP flame retardant is one of the methods for such purpose [4].

Zinc borate (ZB), a white or light yellow crystalline powder, is a new and efficient inorganic fire-retardant [5]. It has been widely used as a flame retardant in plastics, latex and painting materials due to its high thermal stability, fireretardant, and smoke suppression properties. In addition, zinc borate has a good synergistic effect with aluminum hydroxide, magnesium hydroxide, and phosphorus flame retardant. Thus it can decrease the amounts of the flame retardants added in wood and reduce interference of the 
flame retardants with processing capability of the wood. Nano-zinc borate (nZB) has a high ratio of surface area to weight; the smaller the particle size is, the bigger the ratio of surface area to weight is and the better flame retardant effect would be. In addition, nZB can adsorb more smoke and dust per unit weight than regular sizes during wood combustion, due to its good properties described above [6-8].

$\mathrm{APP}$ and $\mathrm{ZB}$ retard flame by producing a carbonaceous foam which can protect the underlying material from temperature raising. Kurt et al., separately, prepared flame retardant composites with $\mathrm{ZB}$ and APP as flame retardants $[9,10]$. The mechanisms of char forming and smoke suppression of $\mathrm{ZB}$ and APP were also investigated [3]. However, few studies on fabricating flame retardant wood by impregnation method using APP and ZB as flame retardants were reported. The permeability of wood is a key factor to fabricate the high level wood-based flame retardant composites. Many attempts have been made to improve the permeability of wood. Wood microwave pretreatment is a new method to improve wood permeability and modify plantation wood. Microwave pretreatment for wood is executed by exposing green wood in a high intensive microwave electromagnetic field over a very short period of time. It causes that moisture inside wood to vaporize quickly and the generated water steam creates a high internal vapor pressure within wood cells cavity. Under such high internal vapor pressure, the weaker elements of wood structures, such as thin-walled cells and pit membranes, are ruptured to form many pathways for easy transportation of vapors and liquids within the wood, which can be used to increase permeability and drying quality of the wood, and provide favorable conditions for preparation of new woodbased composite materials [11]. Many studies indicate that microwave pretreatment for wood can significantly improve the permeability of the wood [12-15]. Researchers at Cooperative Research Center in Australia found that, after high intensive microwave pretreatment, timber volume and capacity of preservative uptake were increased by $13.4 \%$ and 10-14 folds, respectively, but modulus of elasticity (MOR) was reduced by $12-17 \%$ in comparison with untreated wood [16-20]. The overall goal of this work was to fabricate the wood-based flame retardant composites based on microwave pretreated wood and to evaluate some primary properties of the composites by CONE and TGA methods.

\section{Materials and Methods}

2.1. Materials. A green poplar wood of 7 years of age was selected from Yiyang, Hunan, China; ammonium polyphosphate (APP) used in this work was offered by Sichuang Changfeng Chemical Corporation; modified nano-zinc borate (nZB) was purchased from Weifang Fareast Rubber and Plastic Technology Corporation.

2.2. Microwave Pretreatment of Poplar Wood. The microwave pretreatment of poplar wood was carried out by a high intensive microwave pretreatment equipment (MDF-N40, Synotherm Corporation, China) with a microwave power of $12 \mathrm{~kW}$ for $80 \mathrm{~s}$. Wood samples with dimensions of $100 \mathrm{~mm}$ (length) $\times 100 \mathrm{~mm}($ width $) \times 10 \mathrm{~mm}$ (thickness) and moisture content of $60-70 \%$ were placed on a belt moving through a microwave resonator that emits microwave on the sample surfaces uniformly.

2.3. Flame-Retarding Treatment of the Wood Samples. Solutions of APP and nZB were made with water, each at three different concentrations of $5 \%, 10 \%$, and $15 \%$, respectively. The flame retardant treatment of the microwave pretreated wood was carried out within a vacuum-pressure impregnating tank which contains either an APP or nZB solution: first, under a vacuum of $-0.08 \mathrm{MPa}$ for 30 minutes, then change to a pressure of $0.6 \mathrm{MPa}$ for 1 hour. After being airdried at ambient temperature for 2 days, the treated samples were oven-dried at $45 \pm 2^{\circ} \mathrm{C}$ to $10 \%$ moisture content. All specimens were treated firstly in the impregnating tank as described above with three different concentrations (5\%, $10 \%$, and $15 \%$ ) of APP, respectively; optimum concentration of APP was chosen based on CONE analysis of the APPtreated samples; then the sample treated with the optimum concentration of APP was retreated in the same way as described above with three different concentrations (5\%,10\%, and $15 \%$ ) of $\mathrm{nZB}$, respectively, to prepare APP-nZB flame retardant wood composites.

\subsection{Cone Calorimetric (CONE) and Thermogravimetric Anal-} ysis (TGA). The cone calorimetric tests for wood-based flame retardant composites were performed using a Stanton Redcroft (FTT, East Grinstead, U.K) cone calorimeter under a heat flux of $50 \mathrm{kw} / \mathrm{m}^{2}$ and a gas flow rate of $24 \mathrm{~L} / \mathrm{s}$. The samples, with dimensions of $100 \mathrm{~mm} \times 100 \mathrm{~mm} \times 10 \mathrm{~mm}$, were placed under the conical-shaped heater that provided uniform irradiance on the sample surface. Thermogravimetric analysis for wood samples was carried out by a PerkinElmer Pyris 6 Thermal Analyzer at a linear heating rate of $10^{\circ} \mathrm{C} / \mathrm{min}$ under pure nitrogen. The samples $(5-10 \mathrm{mg})$ in powder form were placed in open vitreous silica pans. The measurement temperatures ranged from 30 to $800^{\circ} \mathrm{C}$.

\section{Results and Discussion}

\subsection{Effects of APP Addition on Flame Retardation and Smoke} Suppression of Wood. Heat release rate (HRR, $\mathrm{kw} / \mathrm{m}^{2}$ ) of the woods treated with different concentrations of APP is shown in Figure 1. There were two peaks in HRR curve of untreated sample, which corresponded to the combustion of wood surface and the underlying wood, respectively. The first one appeared at $30 \mathrm{~s}$, and the peak value was $190.7 \mathrm{kw} / \mathrm{m}^{2}$, while the second one was $288.5 \mathrm{kw} / \mathrm{m}^{2}$, appeared at $265 \mathrm{~s}$. It indicates that there were two distinct rapid heat releases that occurred at the untreated wood during its entire combustion course. The profiles of the HRR curves of the APP-treated woods were similar to that of the untreated wood, but it is flatter with the lower pk-HRRs. The pk-HRRs of the APP-treated woods decreased significantly with increasing APP concentration. Compared with the untreated wood, the pk-HRR of the wood treated with $15 \%$ of APP decreased by $63.3 \%$, and the peak time was also deferred by about 


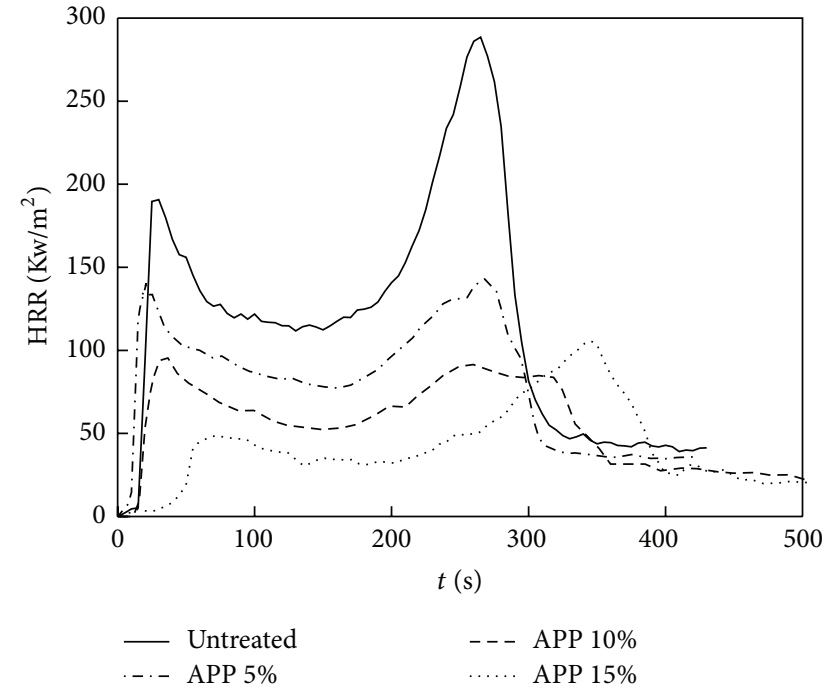

FIGURE 1: HRR curves of the poplar woods treated with different concentrations of APP.

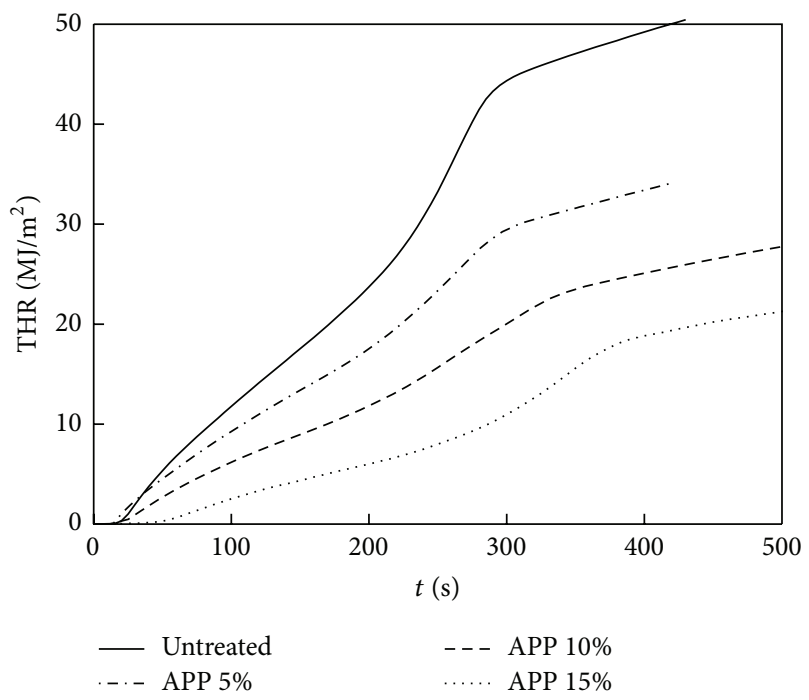

FIGURE 2: THR curves of the poplar woods treated with different concentrations of APP.

78 seconds, which suggested that the pyrolysis process and heat release of wood were suppressed and delayed by APP.

Figure 2 shows the total heat release (THR, MJ $/ \mathrm{m}^{2}$ ) of woods treated with APP at three concentrations of $5 \%, 10 \%$, and $15 \%$, respectively. The THRs of the APP-treated woods decreased with increasing APP concentration, and the heat release process was also slightly delayed. Among the APPtreated wood samples, the one treated with 15\% APP shows smallest THR as $22.32 \mathrm{MJ} / \mathrm{m}^{2}$ whereas the THR for untreated sample as $50.45 \mathrm{MJ} / \mathrm{m}^{2}$.

The total smoke product (TSP, $\mathrm{m}^{2} / \mathrm{m}^{2}$ ) of the woods treated with different concentrations of APP is illustrated in Figure 3. TSPs of APP-treated woods decreased significantly, suggesting that APP effectively suppresses smoke. In comparison with untreated sample, TSPs of the woods treated

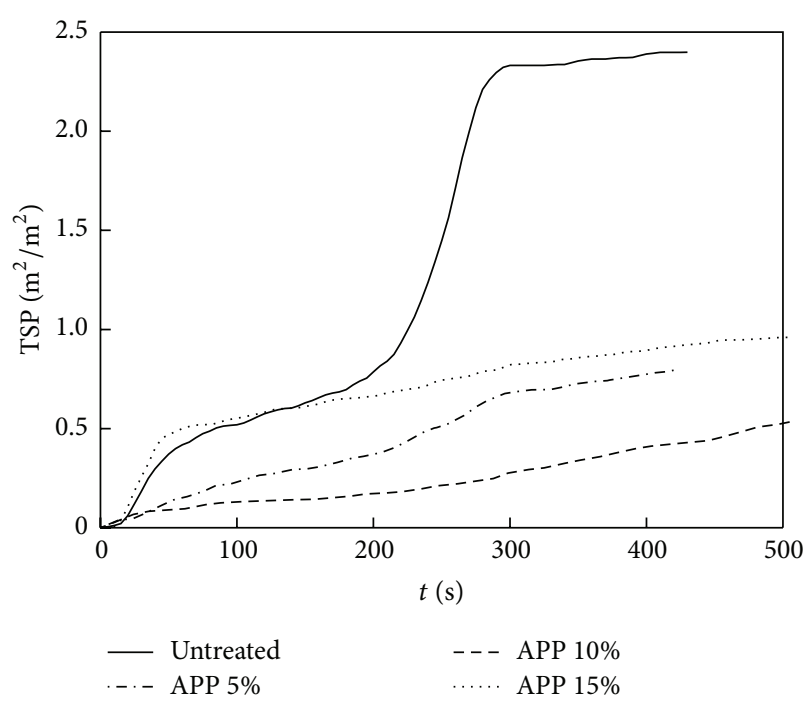

FIGURE 3: TSP curves of the poplar woods treated with different concentrations of APP.

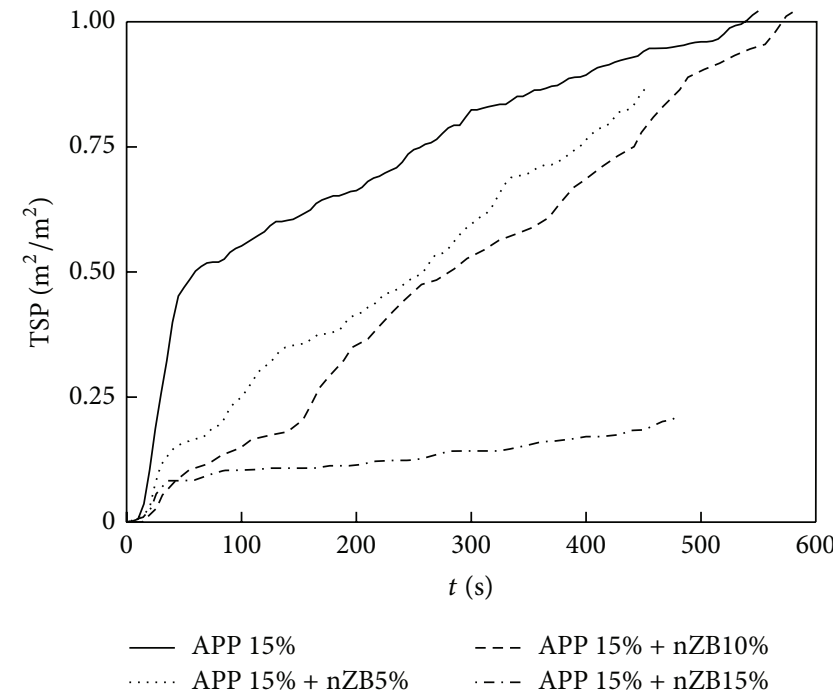

FIGURE 4: TSP curves of APP/nZB-treated woods.

at APP concentrations of $5 \%$ and $10 \%$ decreased by $56.83 \%$ and $69.40 \%$, respectively. However, TSP of the wood treated at APP concentration of $15 \%$ increased rapidly to be higher than those of the wood treated at lower APP concentrations (5\% and $10 \%$ ), implicating that $15 \%$-APP concentration would cause smoke problem.

In summary, from Figures 1, 2, and 3, it is shown that APP executes remarkable flame retardant effects, but unfortunately, at higher concentration (e.g., 15\%), APP generates a relatively high level of smoke, and the mean carbon monoxide yield (Mean COY) increased by $250 \%$ compared with untreated wood, as shown in Table 1 . This is because the fact that upon heating, APP generates a lot of noncombustible gases and moisture which dilute oxygen available to the wood, thus suppressing completion of combustion of the wood and consequently generating toxic gas (e.g., $\mathrm{CO}$ ) and smoke. 


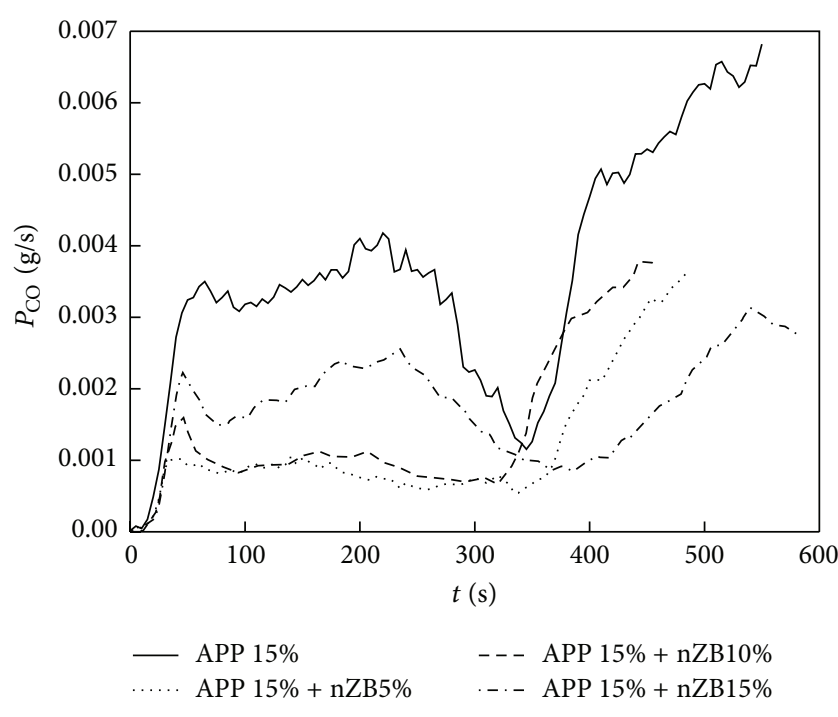

Figure 5: $P_{\mathrm{CO}}$ curves of APP/nZB-treated woods.

Therefore, for safety concern of APP application in woodbased composites, it is necessary to take effective methods to reduce smoke (CO, etc.) generated by APP. Because the wood treated with APP at the concentration of $15 \%$ exhibited wonderful flame retardant properties, and zinc borate has a good smoke suppression effect [6], 15\% APP-treated woods were chosen as samples for smoke-suppression test of nanozinc borate (nZB) in the following study.

3.2. Effects of $n Z B$ Addition on Smoke Suppression of APPTreated Wood. Figure 4 shows the TSP curves of the APPwoods treated with nZB at three concentrations $(5 \%, 10 \%$, and $15 \%)$, respectively. The TSPs of APP and nZB- (APP/nZB-) treated woods significantly decreased with increasing concentration of nZB. At $15 \%$ concentration, nZB reduced TSP as much as $78.43 \%$ compared with that of APP-treated woods, and it reduced TSP to a much lower level than either 5\%or $10 \%$-nZB did. It means that nZB efficiently reduces smoke generated from APP and can be used as an effective smokesuppressing agent in APP-treated wood composites.

CO release rate $\left(P_{\mathrm{CO}}, \mathrm{g} / \mathrm{s}\right)$ of APP-woods treated with $\mathrm{nZB}$ at different concentrations is illustrated in Figure 5. For APPtreated wood sample, there was a peak valley at 350 seconds in its Pco curve, corresponding to the second severe combustion that was from inside-wood burning, as shown in Figure 1. The Pcos of APP/nZB-treated woods were significantly lower than that of APP-treated wood. It indicates that nZB inhibited $\mathrm{CO}$ release from APP-treated woods. Among Pco curves of APP/nZB treated woods, there were two distinct stages around a turning point, the tip of the valley of the Pco curve for untreated wood sample, which was corresponding to the combustion of underlying wood. At 1st stage ( $t=0$ to $350 \mathrm{~s}$ ), Pco of $15 \%$-nZB, that is, APP(15\%)/nZB(15\%)-treated wood, was relatively higher than those of $5 \%$ - and $10 \%$-nZBs, that is, $\mathrm{APP}(15 \%) / \mathrm{nZB}(5 \%)$ - and $\mathrm{APP}(15 \%) / \mathrm{nZB}(10 \%)$-treated woods, but in second stage ( $t=360$ to $600 \mathrm{~s}$ ), the situation was converted to be opposite to that of the 1st stage. Since the 2nd stage responding to the combustion of the bottom wood which causes major damages in a fire disaster, $15 \%$ would be a preferred concentration for nZB treatment of APP-treated wood.

nZB can form a glass-like barrier to block the transfer of the volatile combustibles and heat. When added to APPtreated wood, nZB, together with APP, forms a tighter barrier to further block the feedback between the volatile combustibles and heat to a higher extent, thus converting woodburning into a more limited combustion and decreasing heat (THR) and smoke (TSP) release even more, as Figure 4 and Table 1 show. In addition, $\mathrm{nZB}$ can adsorb $\mathrm{O}_{2}$ from air, and the absorbed $\mathrm{O}_{2}$ can oxidize $\mathrm{CO}$ into $\mathrm{CO}_{2}$, resulting in decreasing Mean COY and increasing Mean $\mathrm{CO}_{2} \mathrm{Y}$ in APP/nZB-treated wood, compared to those in the APP-treated. In comparison with regular sized zinc borate (ZB), nano-zinc borate (nZB) can adsorb more $\mathrm{O}_{2}$ per unit weight, due to its very high ratio of surface area to weight and distribute more evenly in the wood due to its small size, thus exerting its function at a new optimal level.

\subsection{Effects of APP and $n Z B$ Addition on Residual Carbon of} Wood. Figure 6 shows the residues of the wood samples after CONE test. From the figure, it can be found that there were mostly only white ashes left for the untreated wood sample (a), which indicated that the combustion was carried out completely in untreated wood. Figure 6(b) shows that the residual carbon of APP-treated wood is black and relatively thick, indicating that APP promoted charcoal formation. The char layer also shows deep and broad cracks on the surface and bended upward which is a characteristic of intumescent fire-retardant treatments. The residual carbon of APP/nZBtreated wood sample (c) was darker and denser than that of APP-treated wood (b), and the char layer shows a dense texture with fewer crackers at surface, which implies more efficient blockage of transfer of the volatile combustibles and heat within the treated sample during combustion.

3.4. Effects of $A P P$ and $n Z B$ Addition on Thermogravimetric (TG) of Wood. Figure 7 shows the TG curves of different flame retardant systems. The carbon yield of APP-treated wood was much higher than that of untreated wood, and the APP/nZB-treated wood further improved the carbon yield. This shows that APP and nZB effectively promoted charcoal forming. In addition, APP and nZB have a good synergistic flame retardant effect, so that the carbon yield of APP/nZBtreated wood was the highest; the charring effect of the APP/nZB-treated wood was excellent. Meanwhile, there was a cross in curves of APP/nZB-treated wood and untreated wood at $350^{\circ} \mathrm{C}$. Before $350^{\circ} \mathrm{C}$, the curve of $\mathrm{APP} / \mathrm{nZB}$-treated wood was under the curve of untreated wood; however, the situation was opposite after $350^{\circ} \mathrm{C}$. This shows that flame retardants catalyzed the pyrolysis of wood and made the decomposition process in advance, and the starting temperature of pyrolysis is decreasing, which lead to the mass loss rate of APP/nZB flame retardant wood becoming faster before $350^{\circ} \mathrm{C}$. In addition, the direction of decomposition of wood was changed to generate a large amount of charcoal and water 


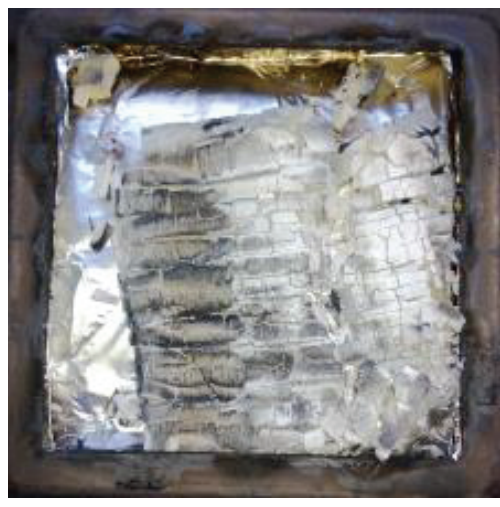

(a) Untreated

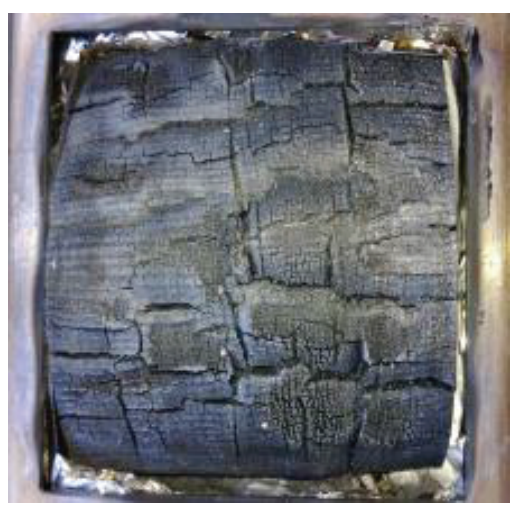

(b) APP 15\%

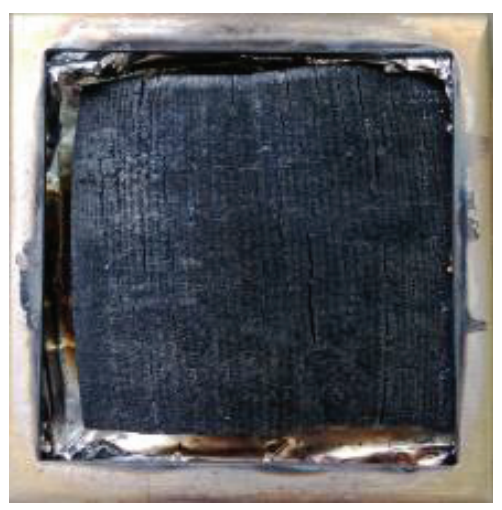

(c) APP $15 \%+$ nZB $15 \%$

Figure 6: Photograph of residues of the wood samples with different flame retardant treatments after CONE.

TABLE 1: CONE data of different flame retardant systems.

\begin{tabular}{|c|c|c|c|c|c|c|}
\hline Sample & $\begin{array}{c}\text { m-HRR } \\
\left(\mathrm{kW} / \mathrm{m}^{2}\right)\end{array}$ & $\begin{array}{l}\text { pk-HRR } \\
\left(\mathrm{kW} / \mathrm{m}^{2}\right)\end{array}$ & $\begin{array}{c}\text { THR } \\
\left(\mathrm{MJ} / \mathrm{m}^{2}\right)\end{array}$ & $\begin{array}{c}\text { TSP } \\
\left(\mathrm{m}^{2} / \mathrm{m}^{2}\right)\end{array}$ & $\begin{array}{c}\text { Mean COY } \\
(\mathrm{kg} / \mathrm{kg})\end{array}$ & $\begin{array}{c}\text { Mean } \mathrm{CO}_{2} \mathrm{Y} \\
(\mathrm{kg} / \mathrm{kg})\end{array}$ \\
\hline Untreated & 121.44 & 288.50 & 50.45 & 2.40 & 0.02 & 1.04 \\
\hline APP $15 \%$ & 43.81 & 105.91 & 22.32 & 1.02 & 0.07 & 0.54 \\
\hline APP $15 \%+$ nZB $15 \%$ & 37.11 & 72.83 & 20.51 & 0.22 & 0.02 & 0.70 \\
\hline
\end{tabular}

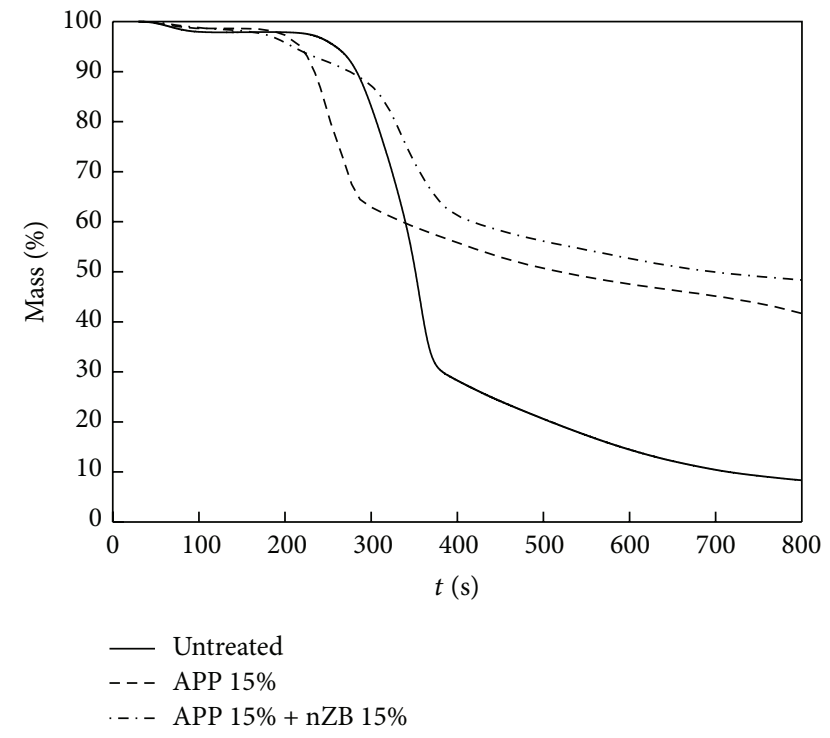

FIGURE 7: TG curves of the wood samples with different flame retardant treatments.

when APP and nZB were added. Therefore, APP/nZB-treated wood had greater residual masses and residual carbon after $350^{\circ} \mathrm{C}$.

\section{Conclusions}

Based on vacuum-pressure impregnating method after high intensive microwave pretreatment, the wood-based flame retardant composites were fabricated, and the effects of ammonium polyphosphate (APP) and modified nano-zinc borate (nZB) addition on flame-retardation and smokesuppression properties of wood were investigated in this study. The results show that (1) APP suppresses combustion and markedly increases carbonization of the wood; (2) compared with untreated wood, the pk-HRR and THR of APPtreated wood sample were reduced by $63.3 \%$ and $55.76 \%$, respectively, when the concentration of APP was at 15\%; (3) the residual carbons increased to be $45 \%$ of the total mass in the APP-treated wood, comparing to $10 \%$ of the total mass in untreated wood. However, the CO's mean yield (Mean COY) of the APP-treated wood was much (3.5 times) higher than that of the untreated wood; (4) with the addition of nZB in APP-treated wood with a concentration of $15 \%$, the TSP and Mean COY of APP/nZB treated wood decreased by 78.43 and $71.43 \%$, compared with APP-treated wood, respectively; (5) nZB further suppresses combustion by reducing $31.23 \%$ of pk-HRR and $8.11 \%$ of THR, and increasing $11.11 \%$ of carbonization (residual carbons); compared with the APPtreated wood, APP and nZB have synergistic effects of flameretardation and smoke-suppression.

\section{Conflict of Interests}

The authors declare that there is no conflict of interests regarding the publication of this paper.

\section{Acknowledgments}

Thanks for the support of the National Natural Science Foundation of China (no. 31370564), New-century Training 
Program Foundation for the Talents by the Ministry of Education of China (NCET-11-0979), and the Graduate Science and Technology Innovation Fund of Central South University of Forestry and Technology (CX2014B09).

\section{References}

[1] C. H. Yao, Y. Q. Wu, and Y. C. Hu, "Flame-retardation characteristics and mechanisms of three inorganic magnesium compounds as fire-retardant for wood," Journal of Central South University of Forestry and Technology, vol. 32, no. 1, pp. 18-23, 2012.

[2] A. A. Klyosov, Wood-Plastic Composites, Wiley-Interscience, Hoboken, NJ, USA, 2007.

[3] Y. C. Hu, Char Forming and Smoke Suppression Function of Zinc Borate and Ammonium Polyphosphate on Wood During Combustion, Central South University of Forestry and Technology, Changsha, China, 2006.

[4] Y. Y. Xia, Y. C. Hu, and Y. Q. Wu, "Preparation of mesoporous $\mathrm{SiO}_{2}$-APP composite flame retardant and effects of flame retardant and smoke suppression on wood," Journal of Central South University of Forestry and Technology, vol. 32, no. 1, pp. 9-13, 2012.

[5] D. G. Su, C. H. Qu, M. F. Zhong, L. Li, and H. Y. Lin, "Study on preparation of nanometer zinc borate and its xylary flame- retardant properties," Journal of Guizhou University of Technology, vol. 37, no. 3, pp. 61-64, 2008.

[6] G. H. Yuan, "Inflaming retarding mechanism and preparation methods of zinc borate nanoparticles," Journal of Ankang University, vol. 23, no. 5, pp. 97-99, 2011.

[7] P. Wang, W. H. Chen, and L. F. Zhen, "Progress on the study of nanometer inorgnic flame retardants in polymeric materials," Journal of Materials Science and Engineering, vol. 21, no. 1, pp. 122-125, 2003.

[8] Z. P. Wu, Y. C. Hu, and W. G. Su, "Effect of ultrafine zinc borate on smoke suppression property of LDPE/IFR system," Plastics Science and Technology, vol. 36, no. 7, pp. 56-60, 2008.

[9] R. Kurt and F. Mengeloğlu, "Utilization of boron compounds as synergists with ammonium polyphosphate for fl ame retardant wood-polymer composites," Turkish Journal of Agriculture and Forestry, vol. 35, no. 2, pp. 155-163, 2011.

[10] N. M. Stark, R. H. White, S. A. Mueller, and T. A. Osswald, "Evaluation of various fire retardants for use in wood flourpolyethylene composites," Polymer Degradation and Stability, vol. 95, no. 9, pp. 1903-1910, 2010.

[11] X.-J. Li, K.-Y. Lu, L.-Y. Lin, Y.-D. Zhou, Z.-Y. Cai, and F. $\mathrm{Fu}$, "Fundamental characteristics of microwave explosion pretreatment of wood I. Properties of temperature development," Forestry Studies in China, vol. 12, no. 1, pp. 9-13, 2010.

[12] Y. X. Lv, Z. H. Xue, and L. Z. Xue, "Observing ex-microcosmic structure of microwave modified wood," Inner Mongolia Forestry Science \& Technology, vol. 4, pp. 31-33, 2001.

[13] T. Jiang, Z. F. Zhou, and Q. W. Wang, "Effects of intensive microwave irradiation on the permeability of larch wood," Scientia Silvae Sinicae, vol. 42, no. 21, pp. 87-92, 2006.

[14] Y.-D. Zhou, F. Fu, X.-J. Li, X.-M. Jiang, and Z.-L. Chen, "Effects of microwave treatment on residue growth stress and microstructure of Eucalyptus urophylla," Journal of Beijing Forestry University, vol. 31, no. 2, pp. 146-150, 2009.

[15] X. J. Li, F. Fu, and Y. D. Zhou, "Effect of microwave pretreatment on permeability of Eucalyptus wood," Journal of Central South
University of Forestry and Technology, vol. 31, no. 12, pp. 145-149, 2011.

[16] M. A. Mekhtiev and G. I. Torgovnikov, "Method of check analysis of microwave-modified wood," Wood Science and Technology, vol. 38, no. 7, pp. 507-519, 2004.

[17] G. A. Harris, G. Torgovnikov, P. Vinden, G. I. Brodie, and A. Shaginov, "Microwave pretreatment of backsawn messmate boards to improve drying quality: part 1," Drying Technology, vol. 26, no. 5, pp. 579-584, 2008.

[18] G. Torgovnikov and P. Vinden, "New wood based materials TORGVIN and VINTORG," in Proceedings of the 5th Pacific Rim Bio-Based Composite Symposium, pp. 756-757, Canberra, Australia, 2000.

[19] K. Sugiyanto, P. Vinden, G. Torgovnikov, and S. Przewloka, "Microwave surface modification of Pinus radiata peeler cores: technical and cost analyses," Forest Products Journal, vol. 60, no. 4, pp. 346-352, 2010.

[20] P. Vinden, G. Torgovnikov, and J. Hann, "Microwave modification of Radiata pine railway sleepers for preservative treatment," European Journal of Wood and Wood Products, vol. 69, no. 2, pp. 271-279, 2011. 

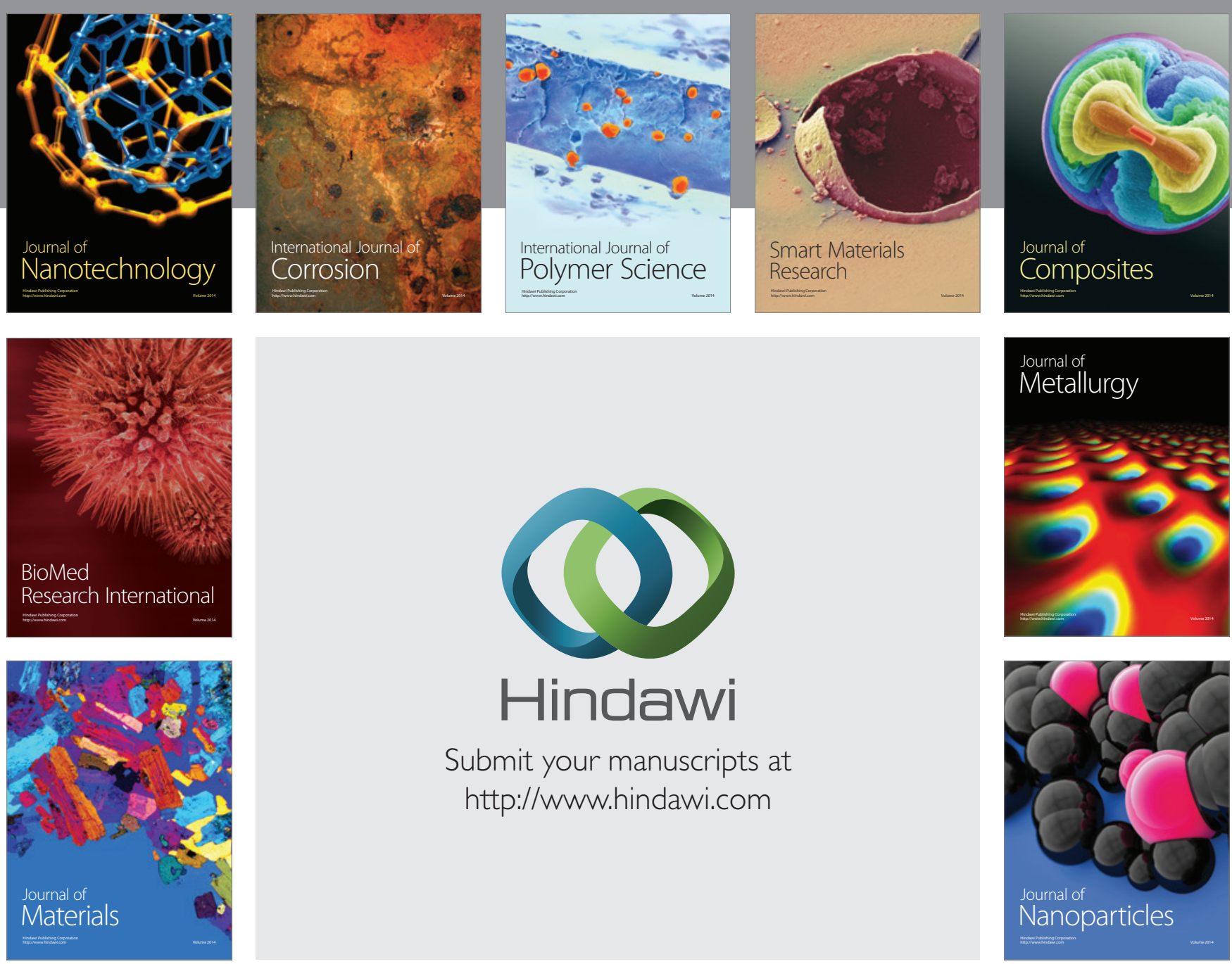

Submit your manuscripts at http://www.hindawi.com
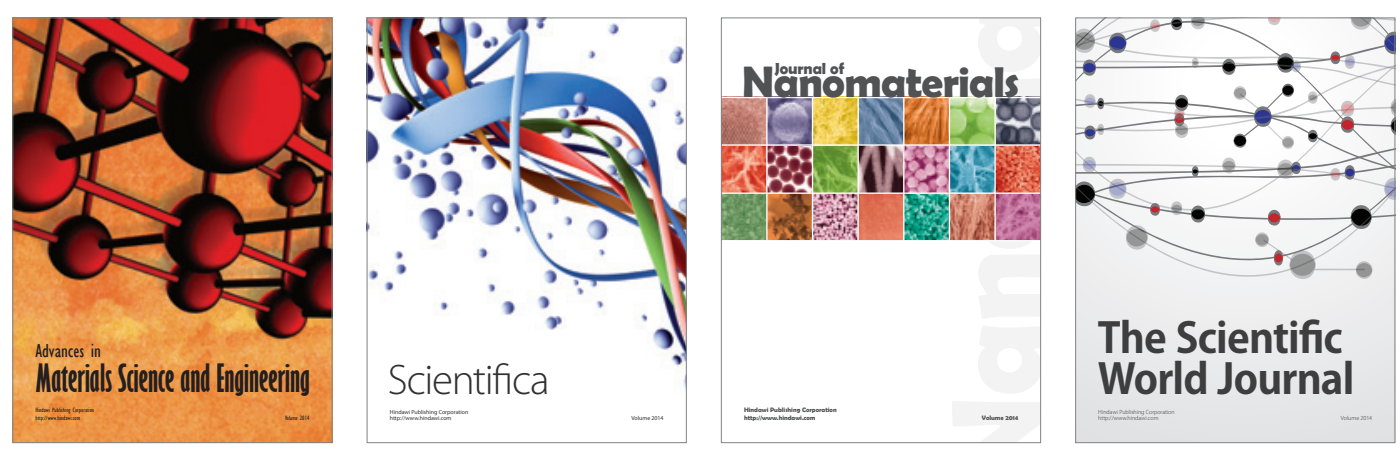

\section{The Scientific World Journal}
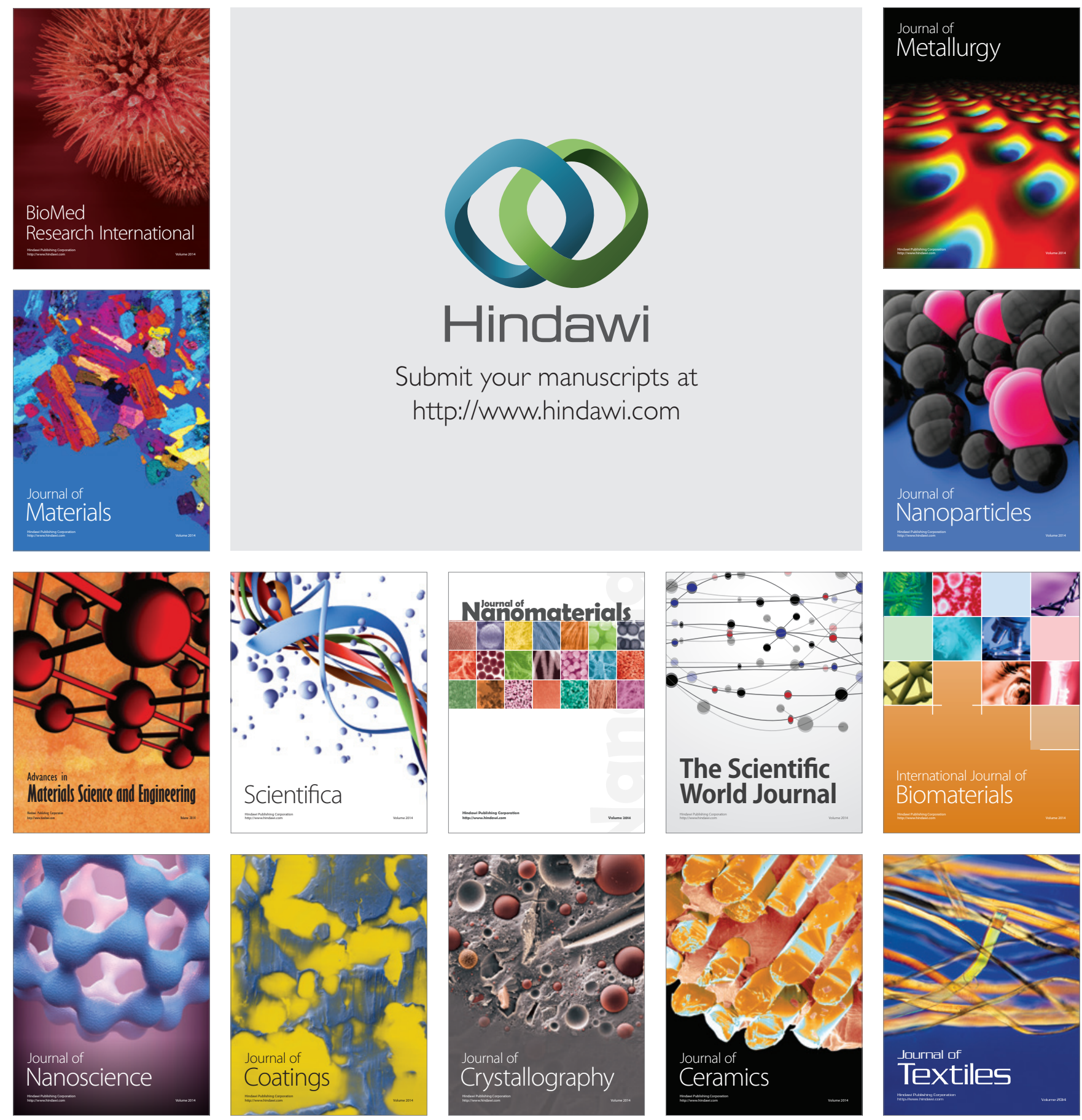